\title{
A Importância da Família na Clínica Infantil: Um Ensaio Teórico-Clínico
}

\author{
Natalia Monti Di Osti \\ Universidade Estadual de Londrina, Londrina, PR, Brasil \\ Núcleo Maria da Penha, Londrina, PR, Brasil \\ Maíra Bonafé Sei ${ }^{1}$ \\ Departamento de Psicologia e Psicanálise da Universidade Estadual de Londrina, \\ Londrina, PR, Brasil
}

\begin{abstract}
Resumo
Entende-se que a família possui grande importância no desenvolvimento da criança. Por meio desta perspectiva, almeja-se discutir o papel da família na psicoterapia de crianças, com um foco na teoria psicanalítica. Trata-se de um estudo teórico-clínico e, assim, parte-se da psicoterapia psicanalítica de uma menina de aproximadamente sete anos de idade, realizada em um serviço-escola de Psicologia. A queixa dos pais relacionava-se à inadequação da criança em contexto escolar e preocupações decorrentes de um discurso depressivo da menina, permeado por falas ligadas ao suicídio. Tais fatos somavam-se à dificuldade de manejo dos pais quanto a essas questões. Optou-se pela realização de encontros com os pais, para acolhimento, escuta e orientação destes. Após estes se percebeu que não apenas a menina havia apresentado mudanças no âmbito da escola e da família, mas também os próprios pais, que antes revelavam dificuldades no manejo com a filha, mostraram-se menos angustiados e melhor preparados para conduzir as situações com a criança. Considera-se que as mudanças da menina não teriam sido tão efetivas se os atendimentos com os pais não tivessem sido realizados concomitantemente aos seus.
\end{abstract}

Palavras-chave: Psicanálise, criança, família.

\section{The Importance of the Family in Children's Clinic: A Theoretical and Clinical Essay}

\begin{abstract}
It is understood that the family has great importance in child development. Through this perspective, the aim of this article was to discuss the role of family in psychotherapy of children, with a focus on psychoanalytic theory. This is a theoretical and clinical study and thus it starts with the psychoanalytic psychotherapy of a girl about seven years old, held in a psychological university clinic. The complaint of the parents was related to the inadequacy of the child in the school context and concerns due to a girl's depressive speech, permeated by speeches related to suicide. Such facts added up to managing difficulties of the parents on these issues. It was chosen to hold meetings with the parents, for acceptance, listening and orientation of these. After these it was realized that not only the girl had shown changes in school and family environment, but also the parents themselves, who previously revealed difficulties
\end{abstract}

Endereço para correspondência: Universidade Estadual de Londrina, Departamento de Psicologia e Psicanálise, Rodovia Celso Garcia Cid, Campus Universitário, PR-445 Km 380, Caixa-postal: 10011, Londrina, PR, Brasil 86057-970. Fone: (43) 3371-4397. E-mail: nati.monti@hotmail.com e mairabonafe@gmail.com 
in handling the daughter, presented themselves less anguished and more prepared to lead the situations with the child. It is considered that the changes of the girl would not have been as effective if the consultations with the parents were not conducted simultaneously to hers.

Keywords: Psychoanalysis, child, family.

\section{La Importancia de la Familia en la Clínica de los Niños: Un Ensayo Teórico y Clínico}

\section{Resumen}

Se entiende que la familia tiene gran importancia en el desarrollo del niño. A través de este punto de vista, el objetivo fue discutir el papel de la familia en la psicoterapia de niños, con un enfoque en la teoría psicoanalítica. Este es un estudio teórico y clínico y así empieza con la psicoterapia psicoanalítica de una niña cerca de siete años, que tuvo lugar en una clínica universitaria de psicología. La queja de de los padres se relacionava con la inadecuación de la niña en el contexto de la escuela y las preocupaciones derivadas de un discurso depresivo de la niña permeado por los líneas vinculadas al suicidio. Los hechos se agregaron a la dificultad de los padres de manejar estas cuestiones. Optamos por la realización de encuentros con los padres, para aceptación, escucha y orientación de estos. Después de estos encuentros fue observado que no sólo la niña había hecho cambios dentro de la escuela y la familia, sino también sus padres, que inicialmente mostraron algunas dificultades en el manejo de la niña, han sido menos ansiosos y mejor preparados para dirigir las situaciones con la hija. Se considera que los cambios de la niña no han sido tan eficaces caso las consultas con los padres no se han sido realizadas al mismo tiempo que los encuentros con la hija.

Palabras clave: Psicoanálisis, niño, família.

Os terapeutas envolvidos da psicoterapia para o público infantil sabem que a família possui extrema importância no desenvolvimento da criança. Tem-se, nas primeiras etapas de vida, uma relação de dependência do indivíduo em relação aos cuidados proporcionados pelos pais, que devem acolher as necessidades da criança no sentido de ofertar um ambiente suficientemente bom para o desenvolvimento saudável de seus familiares (Winnicott, 1963/1983a). No entanto, nos casos de busca pelo atendimento infantil, observa-se frequentemente um cenário oposto a este, no qual se percebe uma dinâmica permeada por sintomas localizados na criança, mas advindos do funcionamento familiar como um todo (Ferrari, 2012).

A partir deste panorama, o presente trabalho tem por objetivo discorrer sobre a psicoterapia de crianças, com ênfase na teoria psicanalítica, debatendo a importância da atenção ao papel da família que traz a criança para o setting. Neste sentido, indica-se compreender setting como algo não apenas relacionado às regras e condições materiais, espaciais e temporais que envolvem o atendimento, como também ao analista e suas ações no sentido de sustentar o processo analítico (Pires, 2002).

Para tanto, parte-se do atendimento clínico de uma menina de aproximadamente sete anos de idade, realizado em um serviço-escola de Psicologia, embasado no referencial winnicottiano somado à contribuição de outros psicanalistas. A queixa principal dos pais relacionava-se à inadequação da criança em contexto escolar. Traziam também preocupações decorrentes de um discurso depressivo da menina, que chegava a mencionar ideias ligadas ao suicídio, fato este somado à dificuldade de manejo dos pais quanto a essas questões. Por meio da experiência clínica, busca-se discutir aspectos concernentes ao sintoma da criança e a psicoterapia infantil, à transmissão psíquica, à família na psicoterapia e à função do analista neste processo. 


\section{O Sintoma da Criança e a Psicoterapia Infantil}

Sabe-se que na clínica psicanalítica com crianças, o paciente - que é a criança - raramente expressa o desejo de tratamento psicoterapêutico (Barbosa, 2010). Esta função quem normalmente realiza são os pais da criança, ou mesmo a escola, que apresentam a queixa e o desejo inicial de que a criança seja tratada. Sendo assim, num primeiro momento, o analista escuta quem solicitou o tratamento - geralmente os pais do paciente - e o aparente sintoma do infante surge como algo que possa incomodar à própria criança, mas incomoda principalmente aqueles que procuraram pelo atendimento.

Em "A Tendência Anti-Social", Winnicott (1956/2000) defende que a tendência antissocial - no caso, como o sintoma aparece pela criança - está relacionada a dificuldades inerentes ao quadro emocional e, sendo assim, pode ser observada em crianças com desenvolvimento normal, podendo ser tratada facilmente se tal medida for atrelada a um ambiente adequado. $\mathrm{O}$ teórico aponta que grande parte do sintoma apresentado pela criança é de origem inconsciente, o que não anula o fato de que possa ser, também, da ordem do consciente. Winnicott (1956/2000) afirma que o que marca a criança antissocial é a esperança de que o ambiente atual possa prover aquilo que já foi ofertado um dia, isto é, através de seus comportamentos mal recebidos pela comunidade, a criança consegue expor um momento de esperança da instauração daquilo que existiu um dia. Tais momentos geralmente são sintomáticos e, em suma, desagradam às pessoas que estão a sua volta.

Em uma das vertentes, a criança procura algo em algum lugar e, fracassando em seu intento, procura-o em outro lugar quando tem esperança. Na outra, a criança busca a quantidade de estabilidade ambiental necessária para suportar o embate do comportamento impulsivo. Trata-se da busca por uma provisão ambiental perdida, uma atitude humana que, por ser confiável, proporciona ao indivíduo a liberdade de mover-se e agir e excitar-se. (Winnicott, 1956/2000, p. 411)
Sendo assim, Winicott (1956/2000) argumenta que na base da tendência antissocial existe uma experiência inicial boa que foi perdida e um dos aspectos essenciais é que o bebê perceba que tal falha foi do ambiente. Tal compreensão provoca a distorção da personalidade e o impulso de buscar a cura numa nova provisão ambiental. A criança passa, então a reivindicar constantemente esta cura pela provisão ambiental, mas não conseguem se beneficiar dela. Desta forma, segundo o teórico, o tratamento da criança sintomática que apresenta comportamentos antissociais relaciona-se ao fornecimento de um ambiente que cuida de fato. $\mathrm{O}$ ambiente deve fornecer uma nova chance para a relacionabilidade do ego, pois a criança percebeu que foi uma falha ambiental referente ao apoio egoico que provocou originalmente a tendência antissocial (Winnicott, 1956/2000).

Por esta via, M. B. J. Ramos e Maggi (2011), respaldados na teoria winnicottiana, apontam que à criança é necessário um ambiente suficientemente bom e facilitador que permita seu desenvolvimento para que esta possa se constituir efetivamente como um sujeito, organizada com base em seu verdadeiro self. Fica claro que, logo que a criança nasce, expectativas já lhe são impostas através dos genitores, do contexto social e cultural e este processo, em si, é importante ao infante, principalmente no que tange aos referenciais que a criança terá frente às suas relações e seus modos de se relacionar, bem como ela mesma irá se ver. No entanto, com a demasiada imposição de expectativas para com a criança, bem como a necessidade de reconhecimento e aprovação social - já que só assim a se criança se percebe amada - corre-se o risco desta não apropriar-se de seu próprio self e viver, em decorrência, diante da superficialidade da expectativa do outro (M. B. J. Ramos \& Maggi, 2011).

Por isso, tem-se a necessidade da criança brincar e se expor na psicoterapia. Segundo Franco (2003), na perspectiva de Winnicott, o brincar permite a comunicação consigo e com os outros, propiciando experiências de desintegração e integração do paciente. O setting analítico funciona como um espaço semelhante ao que foi criado inicialmente entre mãe e bebê. $\mathrm{O}$ 
analista deve compreender a sutileza do brincar e entender que sua função é sustentar o brincar do paciente que é gerado em um espaço e tempo construído transferencialmente. O brincar, de acordo com a teoria winnicottiana, é de extrema importância para que a criança - e também o adulto, enfim, o sujeito em si -, possa expressar suas fantasias e elaborar suas questões, além de propiciar, no processo analítico, que esta possa constituir seu verdadeiro self (Franco, 2003).

Rodrigues e Mishima-Gomes (2013), em uma perspectiva winnicottiana, apontam que a constituição do falso self visa a preservar a continuidade do ser no self verdadeiro ameaçado, tratando-se de uma estratégia de sobrevivência. É possível afirmar que exista um grau de funcionamento falso self na normalidade, correspondente à atitude social. No entanto, em casos extremos esse tipo de organização defensiva pode ocasionar diminuição da capacidade simbólica, pobreza na vida cultural, na criatividade e sentimentos crescentes de futilidade, fugacidade. Observa-se novamente, neste aporte teórico, a necessidade do brincar. Compreende-se que é por meio do brincar que a criança poderá ser criativa e utilizar sua personalidade integral (Winnicott, 1975). Pelo brincar, a criança leva à terapia elementos das experiências de sua realidade e os usa de forma a enriquecer e transformar o campo transicional. É por meio do brincar que há a possibilidade da criança encontrar seu verdadeiro self (Rodrigues \& Mishima-Gomes, 2013).

Desta forma, o brincar só existe se paciente e analista estiverem envolvidos naquele espaço e tempo únicos:

Trata-se de um espaço-tempo teatral, onde se vive, cria-se, sofre-se e alegra-se a dupla paciente-analista, numa dramatização que só tem valor se for investida de afeto e sustentada como se esta brincadeira fosse tão real quanto a realidade socialmente construída. (Franco, 2003, p. 49).

A partir do brincar, o paciente pode criar e criar a si mesmo, isto é, seu self. Para tal, o paciente precisa de um espaço que seja não intencional, isto é, de interação livre. $\mathrm{O}$ ambiente deve proporcionar que o paciente se expresse, mesmo que o fluxo seja desconexo. Só assim, confiante e relaxado, o paciente poderá desenvolver sua criatividade e, assim, seu self. Neste sentido, de acordo com Rodrigues e Mishima-Gomes (2013), o trabalho terapêutico possui como principal finalidade o fornecimento de sustentação emocional. Este vai facilitar o processo interno de amadurecimento da criança.

Para que este espaço seja "não intencional", isto é, para que o ambiente seja facilitador das expressões da criança, é fundamental que tenha se estabelecido a transferência com o paciente. De acordo com Ferrari (2012), a especificidade da terapia infantil trata-se da transferência: os pais ainda estão intensamente presentes no cotidiano da criança e estes podem se colocar resistentes quanto à análise empreendida com a criança. Nos casos nos quais os pais se colocam resistentes, é necessário investir numa análise que envolva/influencie também os genitores, com o analista que se coloca como um mediador entre a criança e o desejo dos pais. Torna-se importante uma intervenção também com os pais, pois o objetivo é que a criança possa se desvencilhar da fantasia narcísica dos pais e possa falar em nome próprio (Ferrari, 2012).

A autora aponta também que se deve pensar nos movimentos resistenciais dos pais diante do desenvolvimento da criança frente a um terceiro - o analista. Com isso, questionar o sintoma da criança, reconduz, muitas vezes, ao questionamento daquelas manifestações a situações que remontam à época constitutiva do infantil dos próprios pais (Ferrari, 2012). Desta maneira, fica evidente que tocar no sintoma do filho, pode desestabilizar os pais e estes podem enfrentar tais questionamentos ou tirar a criança do processo terapêutico, o que é muito comum. Cabe ao psicoterapeuta, então, perceber e entender tais questões, e manejar a situação da melhor maneira possível.

\section{A Transmissão Psíquica}

Sabe-se que o grupo precede o sujeito, isto é, o sujeito quando nasce é inevitavelmente inserido em um contexto, um conjunto subjetivo que mantém o indivíduo como herdeiro dos desejos, renúncias e recalcamentos destes grupos, 
segundo a teoria de Kaës, psicanalista francês (Gutierrez, Castro, \& Pontes, 2011). Além da intersubjetividade cultural a qual todos os indivíduos estão sujeitos desde o nascimento, existe também a intersubjetividade do grupo familiar: tal grupo é o responsável por apresentar lugares, objetos, rituais, ideologias e indicar os limites ao sujeito. Este, por sua vez, torna-se membro do grupo e, então, herdeiro de tais processos subjetivos e é o responsável por construir, organizar e transformar aquilo que é transmitido pelo grupo, sendo o conteúdo elaborado ou não. Este processo não é totalmente vivido de forma passiva por aquele que recebe a herança e há sempre um trabalho de reconstrução na passagem de uma geração a outra (Gutierrez et al., 2011).

Sendo assim, é importante considerar o processo da transmissão psíquica no tratamento infantil, pois é fundamental para compreender as relações patológicas entre pais e filhos e, como consequência, entender as dificuldades no desenvolvimento da criança. Sendo assim, os fatores que compõem a análise da transmissão psíquica entre as gerações - como a importância das relações intersubjetivas, bem como os mecanismos de defesa que servem como suporte frente aos conteúdos não elaborados da família - são muito importantes para entender o funcionamento psíquico da criança, bem como de sua família (Gutierrez et al., 2011).

Sabe-se que o processo de transmissão psíquica coloca em primeiro plano o lado negativo da transmissão, isto é, aquilo que fica oculto, não dito ou mal dito que atravessa as gerações familiares. Quando tal transmissão é então marcada pelo negativo, observa-se que o que é transmitido trata-se daquilo que não pode ser contido, o que não é suportável ao psiquismo dos pais e é depositado no psiquismo da criança (Correa, 2003). A transmissão psíquica, de acordo com a autora, ocorre através de: "1) imagens psíquicas originadas na vida libidinal do sujeito e alimentadas pelas experiências dolorosas dos pais ou ascendentes; e/ou 2) censura e segredos não traumáticos inicialmente, mas que assim se tornam pela confluência de diversas situações" (Correa, 2003, p. 42). Isto é, de acordo com Gutierrez et al. (2011), quando um acontecimento com potencial traumático não é elaborado, ele pode se converter em segredos, silêncios, enigmas, assombrações e possíveis sintomas de bloqueio, "panes" e retenções.

Desta forma, os pais, em geral, são os responsáveis em transmitir à criança os conteúdos familiares, a partir da estrutura de seu psiquismo e inconsciente. A questão colocada é de como a criança irá receber tais conteúdos, como irá incorporá-los, interpretá-los e elaborá-los (Gutierrez et al., 2011).

\section{O Lugar da Família no Atendimento Infantil}

A teoria winnicottiana sobre o amadurecimento pessoal propõe que a mãe e o ambiente de forma mais extensa desempenham um papel fundamental no desenvolvimento saudável do indivíduo. São responsáveis pela inserção da criança no mundo a partir de uma postura pautada no viver criativo (Winnicott, 1960/1983b). Deste modo, J. C. C. P. Telles, Sei e Arruda (2010) apontam que se este processo falha, a criança perde o contato com os objetos subjetivos e, em consequência, perde a capacidade de se encontrar com qualquer coisa de modo criativo, tornando-se submissa à realidade externa. Sendo assim, vale ressaltar a importância de um ambiente suficientemente bom dedicado à criança em seu desenvolvimento: o holding oferecido por seus genitores propicia o exercício do potencial criativo e o viver saudável do bebê. Só assim a criança vai prosseguir num processo de dependência absoluta para a independência relativa.

K. K. P. Telles (2011) aponta que é no seio familiar que o sujeito pode vivenciar seus interesses e necessidades, bem como experienciar conflitos e preparar-se para adentrar e se relacionar com círculos sociais maiores. No entanto, este processo nem sempre acontece. Muitas vezes o ambiente falha além da capacidade da criança em suportar as falhas, haja vista que o ambiente ideal nunca é perfeito, mas sim "suficientemente bom". Estas falhas em demasia acarretam consequências ao psiquismo da criança e ao seu desenvolvimento social, e é neste momento que pode surgir a procura do tratamento. 
M. Ramos (1998) afirma que raramente a família reconhece estar enferma e a queixa geralmente está centralizada em apenas um membro da família, que em muitos casos é a criança, o que acaba por dividir a família entre "membros saudáveis" e "membros doentes". No entanto, sabe-se que na maioria dos casos em que a família projeta suas questões em um membro identificado, elaboram-se algumas questões e vez ou outra acabam por chegar numa questão da família como um todo. Priszkulnik (1995) aponta que a maioria dos pais inicia o tratamento queixando-se da criança e pedindo "dicas" de como lidar com esta. Percebe-se que se a demanda não obtém resposta, os pais começam a falar da própria dinâmica e dificuldades deles surgem em terapia. A escuta psicanalítica permite que as questões que se iniciam como sendo do filho, acabam por abranger a própria vida dos pais.

Sendo assim, é importante que os pais estejam envolvidos com a psicoterapia da criança e cabe ao analista entender e saber manejar a situação para que o melhor encaminhamento seja realizado. Priszkulnik (1995) argumenta que, de qualquer modo, com o envolvimento dos pais ou não, estes sempre aparecerão em análise. Desta forma, alguns autores apontam diversos modos de se trabalhar com os pais na terapia infantil: alguns, como Anna Freud, prezavam apenas por entrevistas com os pais, com cunho de orientação educativa; Melanie Klein considerava de extrema importância a análise do mundo interno da criança, prezando pelo encaminhamento dos pais a outro analista; Dolto e Mannoni tinham como foco escutar os pais em entrevistas, não dando-lhes orientações, mas ajudando a redimensionar as questões da criança e auxiliando, também, na re-situação de suas questões; dentre outros teóricos (Priszkulnik, 1995). Entende-se que não há uma única modalidade de inserção dos pais na terapia da criança, mas compreende-se a importância de se promovê-la.

\section{A Função do Analista}

O analista de crianças, na concepção de Winnicott, é aquele que vai tornar o ambiente à criança similar àquele em que a mãe exerce na função de holding. É uma abordagem frente a um ambiente que fracassou na adaptação das necessidades da criança. Costa (2004) afirma que caberá ao analista, então, ser continente para as necessidades de seu paciente, não se precipitando em interpretações ou com o estabelecimento de diagnósticos. Ao analista é indicada uma comunicação espontânea com a criança. K. K. P. Telles (2011) aborda que é necessário que o paciente atinja o mínimo de maturação para que qualquer interpretação possa ser útil. Portanto, quando se ocorre uma falha no desenvolvimento do paciente, o terapeuta deve proporcionar um ambiente que se adapta às necessidades do indivíduo, assim como a mãe suficientemente boa se adapta às necessidades do bebê. Assim, Winnicott como um psicanalista não ortodoxo, apontou que o terapeuta tem liberdade de usufruir do setting e manejá-lo da melhor maneira a cada paciente, oferecendo um ambiente suficientemente bom que se adapte às suas necessidades (K. K. P. Telles, 2011).

Melo (2003), respaldada pela teoria winnicottiana, afirma que o analista deve deixar a criança livre em sessão e permitir que o paciente se comunique de sua forma, por meio de sucessões de ideias, pensamentos, impulsos e sensações sem um aparente sentido ou conexão, mas que é a forma deste manifestar seu material simbólico. É papel do analista buscar remover os bloqueios que possam surgir em tais sucessões. Tal remoção permite que a criança possa realizar o processo de recordar, repetir e elaborar fundamentado por Freud, conduzindo-a para novas formas de significação e desenvolvimento. Sendo o analista importante no processo de acolher as demandas do paciente e auxiliar nas formas de elaboração, posteriormente a criança irá aprender com suas próprias experiências, a saber, lidar com suas dificuldades (Costa, 2004).

\section{Metodologia}

\section{Delineamento}

Trata-se de um estudo qualitativo (Turato, 2005) e, como tal, fornece maior flexibilidade ao pesquisador em relação aos recursos e métodos de investigação e análise. Respaldou-se no refe- 
rencial psicanalítico winnicottiano, delineado a partir do formato de um estudo de caso (Peres \& Santos, 2005). Organizou-se como um estudo teórico-clínico e, assim, procurou relatar, analisar e discutir o tema proposto a partir do caso clínico da psicoterapia de uma criança empreendida em um serviço-escola de Psicologia.

Assinala-se que a presente pesquisa insere-se em uma investigação mais ampla que almeja estudar processos e fenômenos implicados na psicoterapia psicanalítica no contexto institucional. Foi aprovada pelo Comitê de Ética em Pesquisa com Seres Humanos da Universidade Estadual de Londrina, a partir do parecer 017/2014, com assinatura do termo de consentimento livre e esclarecido por parte dos participantes.

\section{Participantes}

Este estudo foi realizado a partir do atendimento de uma menina - Júlia (nome fictício) - de sete anos de idade, com a principal queixa citada pelos pais de mau comportamento na escola, bem como discursos considerados de risco pelos pais, como a vontade da menina em se suicidar. Ademais, os pais de Júlia - Alberto e Elisa (nomes fictícios) - foram atendidos no serviço-escola a fim de construir um espaço de escuta e para que orientações fossem realizadas com relação ao caso da menina.

\section{Procedimentos}

Foi realizada a psicoterapia psicanalítica de uma criança encaminhada para um serviço-escola de Psicologia, com foco nas contribuições de Winnicott. O processo foi iniciado com uma entrevista com os pais de Júlia. Em seguida, ocorreram os atendimentos da menina com sessões semanais de aproximadamente 50 minutos de sessão, por aproximadamente nove meses. Poucas faltas ocorreram e, em sua maioria, foram justificadas pela mãe da paciente. Os atendimentos com os pais foram realizados mensalmente, convocados pela terapeuta, com o mesmo tempo de sessão da menina - 50 minutos -, ou por solicitação dos mesmos. Todas as sessões foram transcritas após cada atendimento para posterior supervisão, haja vista tratar-se de um serviço- -escola de Psicologia que demanda a realização destes registros e busca cumprir o papel de se configurar como um espaço para ensino, pesquisa e extensão.

\section{Instrumentos}

Considera-se que na análise de crianças, a forma de comunicação se dá a partir de jogos, ações e brincadeiras, que estão repletos de significado (Avellar, 2004). Sendo assim, os atendimentos realizados no serviço-escola de Psicologia contaram com alguns instrumentos importantes no processo analítico, sendo eles: uma gaveta, em que paciente e analista possuíam cada uma a cópia da chave e somente ambas possuíam acesso à mesma à semelhança da caixa lúdica proposta por Aberastury (1982). Esta gaveta continha materiais artístico-expressivos - como lápis de cor, canetinhas, giz de cera, massinha de modelar, tinta guache e aquarelada, giz de lousa, folhas sulfites de diversas cores, cola, tesoura, dentre outros materiais -, bem como uma pasta etiquetada pela própria paciente contendo os trabalhos realizados entre a menina e a analista em sessão. Além da gaveta, os atendimentos contavam com uma sala com inúmeros brinquedos que podiam ser escolhidos pela paciente a qualquer momento da sessão, sendo levados ao setting. Neste sentido, tem-se uma adaptação do contexto terapêutico à realidade institucional, tal como indicado por Silva e Ribeiro (2011). Tais autores expõem a realidade de um serviço-escola de Psicologia de uma universidade pública na qual as crianças podem dispor dos brinquedos contidos em um armário coletivo, de forma similar ao contexto aqui retratado.

\section{Resultados}

\section{Entrevistas com os Pais}

Os pais de Júlia procuraram o atendimento mostrando-se muito angustiados pela filha. Disseram que a menina se comportava inadequadamente na escola, que não tinha amigos, era muito ressentida. Não sabia brincar (extrapolava os limites, segundo o pai) e, quando brincava, só o fazia com adultos. Tentava muito agradar aos 
outros, faltava-lhe atenção, além de apresentar alguns discursos depressivos, como querer se suicidar por não conseguir obedecer à mãe, dentre outros sintomas relatados pelos pais.

Alberto e Elisa formam um casal relativamente jovem e com histórias de vida, aparentemente, diferentes. Elisa viveu muito tempo em um país vizinho, em uma propriedade rural. Sofria muito com a educação rígida dos pais. Ela conta que apanhava muito quando era pequena e, que na maioria das vezes, não sabia o motivo. Informa que tinha muito medo dos pais. Alberto perdeu os pais quando era ainda adolescente e não possui muita intimidade com os irmãos. Ele fala pouco em sessão e Elisa monopoliza as falas, inclusive quando o assunto diz respeito ao marido. Contou que foi criado "muito solto" e que isso não o prejudicou, mas que não tem amigos e não faz questão de manter contato social, até mesmo com sua família. Diferentemente de Elisa, que sempre procura os familiares e possui extremo contato com eles. Ambos são evangélicos participantes e possuem uma abordagem rígida quanto à educação das filhas (Júlia possui uma irmã mais nova) e quanto a si mesmos.

Elisa confessa nas entrevistas que espancava Júlia quando esta era muito pequena ainda. Quando questionada sobre o motivo, diz que foi assim que aprendeu a educar e que não gostaria que a filha saísse de perto dela jamais, pois no sítio onde morou sofreu uma tentativa de abuso sexual e isso a deixou extremamente traumatizada. Desta forma, Júlia não pode sair para brincar (só se for à casa de algum familiar e mesmo assim deve estar acompanhada pela mãe), apenas receber amigos em casa sob a custódia da mãe. Um dos apontamentos dos pais é que Júlia não gostava de brincar e que gostava muito de realizar serviços domésticos (o que se confrontou com o discurso e atitudes da menina em sessão).

Também apontaram a dificuldade de saber lidar com a menina frente aos problemas da escola. Júlia recebe muitas reclamações da escola quanto a seus comportamentos: afirmam que é muito competitiva, que não possui amigos por conta de seu jeito, que não se dá bem com as professoras, que se sente vitimizada, que demanda muita atenção apenas para ela, dentre outras reclamações. Diante de tais reclamações, advindas de Júlia e da própria escola, os pais começam a duvidar da veracidade do que a filha aponta e acabam por pedir que ela não mais conte a eles a respeito dos acontecimentos na escola. Outra orientação citada pela mãe é a de pedir que Júlia se mantivesse passiva frente às situações e não se manifestasse de maneira alguma. A menina passou a seguir algumas destas atitudes, o que a deixou ainda mais angustiada frente suas questões.

Outra questão citada pelos pais é a inadequação da menina em espaços públicos: apontaram que ela não consegue se comportar na igreja - se levanta a todo o momento, precisa ir ao banheiro com frequência -; quer brincar apenas com adultos e, segundo os pais, não possui limites em suas brincadeiras; e, principalmente, que é muito fixada em tecnologia. Júlia não possui televisão, videogame ou computador em casa e, quando vê, quer brincar até enjoar e isso leva muito tempo, fazendo com que ela acabe abandonando outros tipos de brincadeiras, ou não queira mais fazer outra coisa.

Durante algumas sessões com os pais - solicitados pela terapeuta ou pelos próprios -, o principal foco das sessões era o comportamento de Júlia na escola. Certa vez, Júlia relatou aos pais que gostaria de bater com a cabeça ao chão até morrer, pois não conseguia obedecer aos pais (não conseguia fazer o que pediam a ela), principalmente ao que se referia a seus comportamentos na escola. $\mathrm{O}$ corpo docente, por várias vezes durante o tratamento da menina, pediu que fizessem avaliação psicológica de Júlia, pois relatavam que a menina não tinha déficit cognitivo, mas inferiam que esta possuía algum déficit emocional. Só assim entenderiam o que se passava com a menina e saberiam lidar com ela. Além disso, os pais relataram não ter muita paciência em ensinar e acompanhar os estudos da menina e que não permitiam que esta fizesse "bagunça" em casa: como brincar com giz, com massinha, tinta, dentre outras.

Nas últimas sessões com os pais, após os espaços de escuta oferecidos e as orientações dadas quanto a como lidar com a filha, estes relataram que o atendimento havia sido muito proveitoso 
para eles e Júlia: que esta brincava mais, não realizava mais serviços domésticos, brincava com amiguinhos em casa e não recebia mais tantas reclamações da escola. A mãe relatou não espancar mais a menina e que a deixava mais livre quanto às brincadeiras: permitiu que esta se sujasse mais, brincasse com materiais mais livres.

\section{Os Atendimentos com Júlia}

Júlia chegou aos atendimentos sem entender o motivo. Quando questionada sobre o porquê estava na clínica, dizia que era porque não obedecia aos pais. Parecia ser muito tímida e pouco falava. Chegou à terapia com um discurso marcado pela fala dos pais: repetia tudo o que eles disseram, mas quando questionada se eles haviam comentado algo da primeira entrevista, dizia que não. Inicialmente, as brincadeiras de Júlia em sessão eram muito vinculadas a serviços domésticos: preocupava-se em cozinhar, lavar e passar e parecia se sentir bem realizando tais atividades. No entanto, com o passar das sessões e o estreitamento do vínculo, a menina passou a dizer mais sobre si e um dia escapou-lhe que não gostava de fazer serviços domésticos, mas que a mãe lhe pedia para realizá-los. Ao passo em que a transferência se instalava, a terapeuta buscou colocar à menina que ela poderia dizer e fazer tudo o que quisesse, que nada seria contado a seus pais, a menos que ela mesma o fizesse, mas que não havia necessidade. Este discurso foi dito à Júlia durante todo o tratamento, pois a menina demonstrava dificuldades em expressar seus pensamentos e sentimentos. Desta forma, além dos inúmeros jogos aos quais Júlia tivera acesso, também foi disponibilizada sua gaveta com materiais somente dela, que apenas a menina e a terapeuta possuíam o acesso - cada uma tinha a cópia da chave da gaveta -, para que lá tudo o que produzissem fosse guardado e apenas ambas, se quisessem, poderiam acessar.

O uso da gaveta foi muito simbólico à Júlia: por vezes, a garota perguntava desconfiada se alguém havia aberto a gaveta; ou se a terapeuta nunca esquecia a chave, pois sempre estava consigo; se nenhuma outra criança tentava abri-la, já que era uma sala em que muitas crianças são atendidas e cada uma possui uma gaveta; dentre outras perguntas. Júlia revezava os atendimentos entre ficar com os materiais da gaveta e usufruí-los, ou pegar jogos na sala ao lado. Muitas vezes, nas saídas de Júlia, percebeu-se que a menina se mostrava resistente diante de alguma situação desconfortável trabalhada em sessão e que, por vezes, queria explorar o ambiente da clínica. Dentre as produções feitas por Júlia, observou-se que ela detinha-se mais em desenhar algo do concreto - como animais, insetos, árvores - do que do fantasioso. Também demonstrou enorme dificuldade em fazer algo seu: sempre que podia, realizava os desenhos conforme a terapeuta os fazia, copiando até mesmo as cores e o estilo do desenho, descaracterizando o próprio (achava seus desenhos feios, não confiava em seu potencial). Mesmos nos jogos, a menina prezava por escolher sempre os mesmos - em geral de derrubar coisas, ou de montar, ou de tabuleiros - e subvertia as regras dos jogos para suas próprias e, nesta configuração, o jogo ficava mais difícil ainda, ou menos interessante de se jogar.

Era notável, também, que Júlia atentava-se muito ao tempo da sessão. Caso a terapeuta chegasse atrasada, ou se a sessão terminasse pouco antes do combinado, Júlia mostrava-se ansiosa e sinalizava isso à terapeuta. Além disso, durante a maioria das sessões, a menina perguntava muitas vezes sobre as horas, se a sessão já estava acabando, demonstrando que não conseguia concentrar-se no presente e aproveitar a sessão. Era frequente algum tipo de questionamento frente à vida pessoal da terapeuta: tem filhos? É casada? Evangélica ou católica? Tem irmãos? Animais? Percebeu-se que a menina realizava comparações de sua vida pessoal com a da terapeuta e, muitas vezes, idealizava a vida de sua psicóloga.

Algumas vezes, Júlia demonstrou em sessão anseios com relação à transgressão. Filha de um casal evangélico praticante, a menina possui um cabelo enorme, sempre usando calça comprida ou saias longas, raramente de shorts - e se assim usar, sendo uma bermuda comprida. Não pode usar brincos, colares, anéis e maquiagem e, além disso, não pode possuir televisão, videogame ou computador. Por vezes, Júlia elogiou a terapeuta, bem como suas vestimentas e acessórios, principalmente aquelas coisas que lhe são proi- 
bidas. Quando questionada se gostaria de usar, afirmava por vezes que gostaria e em outras que não. Em algumas sessões, apareceu com sapatos de salto, alguns brilhantes e por vezes com acessórios. Afirmava que a mãe não se importava muito, mas que o pai não gostava que ela usasse tais coisas. Acredita-se que nestas ocasiões provavelmente o pai não viu como Júlia saiu de casa: Alberto trabalhava desde muito cedo e não acompanhava a menina em terapia. Na maioria das vezes quem levou Júlia às sessões foi Elisa. Também demonstrava enorme curiosidade em novelas e desenhos e sempre perguntava sobre o assunto à terapeuta, visto que ela mesma tinha pouco ou nenhum acesso.

Quando questionada a respeito de seus amigos, Júlia afirmava que não os possuía, mas que gostaria de tê-los. Dizia que na escola, seus colegas a consideram uma criança chata e nunca podia ir a festas de aniversário ou brincar na casa dos colegas, pois os pais não deixavam. Da mesma forma, poucos eram os amigos que iam até sua casa, restringindo seu contato apenas com os poucos primos de sua idade. Júlia afirmava não gostar de brincar com a irmã e com seus primos por serem menores que ela. Desde sempre deixou clara a sua preferência por brincar com crianças de sua idade, ou mais velhas e até mesmo adultos. Percebeu-se durante as sessões, também, que Júlia não permitia que as brincadeiras saíssem de outra forma que não de seu jeito, demonstrando uma postura controladora. A postura de controle não partia apenas das brincadeiras, mas também em outros sentidos: se algo saísse fora do controle de Júlia, a menina mostrava-se desesperada.

Outro fator apontado pelos pais e pela escola (a terapeuta foi até a escola conhecer o corpo docente de Júlia) e também percebido como projeção da menina sobre a terapeuta foi o fato de Júlia agradar as pessoas quando quer algo, ou quando não quer que algo aconteça e até mesmo quando está sentindo sentimentos contrários às suas ações. Por exemplo: Júlia, sendo uma criança muito competitiva e não admitir perder. Quando perdia algum jogo da terapeuta, a abraçava e beijava muito, sem motivo algum. Inicialmente, quando questionada pela terapeuta sobre o que estava sentindo, dizia sentir-se bem e não se incomodar. Com o passar das sessões, conseguiu dizer que se sentia com raiva em ter perdido o jogo.

A maioria das atividades realizadas entre Júlia e sua terapeuta, resumiu-se a brincadeiras de "professora e aluna". Por vezes, a menina era a professora e por outras, a terapeuta. Percebeu-se que Júlia reproduzia, na sessão as atitudes de sua professora, demonstrando como é a prática desta em sua sala de aula e, por vezes, como Júlia gostaria que fosse. Nas interpretações da terapeuta enquanto professora, Júlia pedia que esta fosse rígida e a corrigisse sempre. Esta mesma se corrigia: escrevia e apagava por vezes, jogava folhas de sulfite fora por apagar demais. Júlia sempre demonstrou certa exigência consigo e com os outros em sessão. Por esperar muito de si, percebeu-se que Júlia esperava muito das outras pessoas também, o que raramente (ou nunca) acontecia conforme seu desejo.

Aproximando-se do encerramento da terapia, Júlia demonstrou certa ansiedade na separação, pegando muitos jogos para jogar e jogando-os rapidamente para que outro pudesse ser aproveitado; se desenhava, assim fazia com rapidez, para que outra atividade pudesse ser realizada; dentre outros fatos percebidos pela terapeuta. Passou a brincar muito mais - principalmente com tintas, com giz de cera e também pulando, dançando, atitudes que Júlia não realizava antes - e passou a ser mais expressiva e espontânea, não se importando tanto mais frente às reações de sua terapeuta.

\section{Discussão}

Júlia chegou à clínica psicológica como a paciente identificada pela família, portadora do sintoma familiar. Inicialmente, à luz da queixa dos pais, percebeu-se a enorme dificuldade de Alberto e Elisa ao lidarem com os sintomas apresentados pela filha. Ficava claro que ambos não se responsabilizavam por tais sintomas e não entendiam o porquê da menina se comportar de determinadas formas, se estes possuíam uma educação considerada rigorosa. Ao longo das sessões com Júlia, percebeu-se que muitos dos 
sintomas da menina apresentavam-se como consequências de um ambiente não suficientemente bom (Winnicott, 1956/2000) oferecido por seus genitores. Júlia era espancada pela mãe quando muito pequena e o pai sempre se mostrou muito passivo frente às atitudes de Elisa, mesmo não concordando com tais. Escutando ao casal, compreendeu-se que ambos não tiveram um ambiente suficientemente bom quando crianças. Elisa apanhava muito e tinha pais extremamente rígidos em sua educação e Alberto perdeu os pais quando criança e, segundo o próprio, "criou-se sozinho na vida". Entendeu-se que não possuem condições psíquicas de oferecer um ambiente propício à Júlia, que veio sendo depositária dos sintomas dos pais até então.

Atendendo ao casal, percebeu-se que ambos possuíam cargas emocionais fortíssimas do passado e que não foram elaboradas e muitas delas eram transferidas para Júlia pelo mecanismo da transmissão psíquica (Correa, 2003). Um exemplo claro pôde ser observado quando Elisa relatara que sofreu uma tentativa de abuso quando tinha apenas nove anos de idade e apanhava muito dos pais sem saber o motivo. Por não ter elaborado tais questões - e isto pôde ser percebido, pois em todos os atendimentos com o casal, Elisa trouxera tais questões e se emocionara muito -, percebeu-se que Elisa repetiu o que viveu com Júlia, agredindo a menina por não querer que esta saísse de perto de seus cuidados e proibindo a menina de se relacionar com outras pessoas e sair de casa. Cabe também lembrar que a menina chegou à terapia com sete anos e logo se aproximava a idade do abuso nove anos.

Outro ponto a ser colocado é que o pai não consegue manter vínculos afetivos de outra ordem que não a familiar. Não faz questão de ter amigos e de manter contato com familiares mais distantes. Também se percebeu nos atendimentos certa apatia por parte de Alberto, que deixava Elisa discursar até mesmo por ele e pouco falava apenas quando the era convocado. Tais sintomas apareceram ressonantes em Júlia, que em sessão apresentava alguns sintomas de apatia (não queria brincar, não sabia o que queria fazer em sessão, brincava de forma entediante) e também afirmara não fazer questão de possuir amigos ou brincar em outros locais que não sua casa (o que logo se contradisse em sessão, quando Júlia afirmou, certa vez, sobre seu desejo de brincar fora de casa e com crianças de sua idade).

Quando Júlia chegou para ser atendida, percebeu-se que a menina apenas detinha-se em brinquedos que faziam menção a serviços domésticos. Além disso, quando brincava com outros brinquedos, ou fazia o uso dos recursos artísticos de sua gaveta, apresentava pouca criatividade e fantasia, remetendo-se mais às brincadeiras e produções da ordem do concreto. Ademais, Júlia apresentava forte necessidade em agradar a terapeuta, assim como fazia com Elisa, com sua professora e com adultos em geral. Percebeu-se que procurava manter uma postura rígida, assim como the era transmitido através de sua educação. Isto é, mesmo em um ambiente em que era oferecido à menina poder fazer e dizer o que quiser, Júlia preferia "seguir à risca" o desejo dos pais e de seus professores, revelando certa resistência quanto à construção de si enquanto sujeito pautado em seu verdadeiro self (M. B. J. Ramos \& Maggi, 2011).

No entanto, Júlia apresentava comportamentos considerados inadequados por seus educadores em seus espaços de socialização: na igreja e na escola. Na igreja, a mãe afirmara que Júlia não conseguia manter-se quieta e sempre solicitava ir ao banheiro. Na escola, além de solicitar ir ao banheiro, mostrava-se competitiva com os colegas, dispersa e manipuladora - de acordo com a professora - e ia com frequência à direção da escola por reclamações da professora. A hipótese de tais comportamentos pode ser respaldada pela teoria winnicottiana da tendência antissocial: a criança passa a reivindicar a cura em seu ambiente atual, buscando aquilo que um dia teve em seu ambiente primário; no entanto, não consegue se beneficiar disso. Isto é, Júlia buscou chamar a atenção dos pais para si, revelando alguns comportamentos indesejados na escola e discursos chocantes aos pais, no sentido de resgatar o cuidado que foi ofertado um dia. Winnicott (1956/2000) aponta que o tratamento para a criança antissocial é o fornecimento de um ambiente que de fato cuida e dá 
respaldo para que seu ego seja fortalecido e seu verdadeiro self possa emergir.

Neste sentido, a terapeuta procurou oferecer à Júlia um ambiente suficientemente bom, em que esta pôde se expressar de diversas formas, principalmente através das brincadeiras. Júlia pôde compreender o prazer que a brincadeira pode trazer e os benefícios de ser mais espontânea e se expressar. Dificuldades existiram quanto ao trabalho transferencial, mas aos poucos Júlia conseguiu livrar-se de algumas resistências e estreitar o vínculo com a terapeuta.

Aos pais de Júlia, percebeu-se certo alívio durante o percorrer do tratamento. Chegaram afoitos à clínica e com o espaço de escuta oferecido e das orientações da terapeuta, observou-se maior tranquilidade dos pais quanto ao lidar com a menina e quanto às questões deles. Foi sugerido ao casal que fizessem terapia familiar por meio de um projeto oferecido na mesma instituição. No entanto, Alberto não aderiu à sugestão de encaminhamento e Elisa foi encaminhada ao atendimento individual, para que suas questões fossem trabalhadas.

\section{Considerações Finais}

Júlia foi encaminhada para a psicoterapia por apresentar queixas referentes a maus comportamentos na escola e discursos de risco, como querer suicidar-se por não conseguir obedecer aos pais. Por meio das sessões realizadas com os pais e com o processo terapêutico de Júlia, pôde-se hipotetizar que tais sintomas apresentados pela menina provinham de uma falha no ambiente em que a menina esteve inserida. Diante do que se pôde observar nas sessões, Júlia possuía grande dificuldade em falar por si e estabelecer vínculo com a terapeuta, bem como imaginar e explorar sua criatividade. Tal fato pode supor que Júlia teve uma possível falha na constituição enquanto sujeito, a partir de seu verdadeiro self.

Após as consultas realizadas com os pais, no sentido de oferecer um espaço de acolhimento, escuta e orientação, percebeu-se que não apenas Júlia havia melhorado, mas também Alberto e Elisa. Estes antes revelavam dificuldades no lidar com a filha e, posteriormente, mostraram- -se menos angustiados e melhor preparados para conduzir as situações com Júlia. Pensa-se que a melhora gradual de Júlia não teria sido tão efetiva se os atendimentos com os pais não tivessem sido realizados concomitantemente aos seus. Acredita-se que com o encaminhamento da mãe à terapia individual há grande perspectiva de melhora no caso de Júlia. Tal aspecto aponta para a importância de um olhar mais extenso do psicoterapeuta de crianças para a família como um todo, propondo intervenções que possam acolher não apenas a criança em seu sofrimento psíquico, como também o grupo familiar, responsável pela oferta de um ambiente propício à saúde de seus membros.

\section{Referências}

Aberastury, A. (1982). Psicanálise da criança: Teoria e técnica. Porto Alegre, RS: Artes Médicas.

Avellar, L. Z. (2004). Jogando na análise de crianças: Intervir-interpretar na abordagem winnicottiana. São Paulo, SP: Casa do Psicólogo.

Barbosa, M. E. S. (2010). O brincar na psicanálise: Do objeto transicional a constituição do sujeito [Monografia]. Recuperado em http://repositorio. favip.edu.br:8080/bitstream/123456789/656/1/ TCC + COMPLETO.pdf

Correa, O. B. R. (2003). Transmissão psíquica entre as gerações. Psicologia USP, 14(3), 35-45.

Costa, T. (2004). Psicanálise com crianças (Vol. 75). Rio de Janeiro, RJ: Zahar.

Ferrari, A. G. (2012). Sintoma da criança, atualização do processo constitutivo parental? Tempo Psicanalítico, 44(2), 299-319.

Franco, S. D. G. (2003). O brincar e a experiência analítica. Ágora: Estudos em Teoria Psicanalítica, 6(1), 45-59. doi:10.1590/S151614982003000100003

Gutierrez, D. M. D., Castro, E. H. B., \& Pontes, K. D. S. (2011). Vínculo mãe-filho: Reflexões históricas e conceituais à luz da Psicanálise e da Transmissão Psíquica entre gerações. Revista do Nufen, 1(2), 3-24.

Melo, M. B (2003). Interpretação do brincar na clínica psicanalítica [Monografia]. Recuperado em http://repositorio.uniceub.br/bitstream/123456789/2837/2/9857476.pdf 
Peres, R. S., \& Santos, M. A. (2005). Considerações gerais e orientações práticas acerca do emprego de estudos de caso na pesquisa científica em Psicologia. Interações, 10(20), 109-126.

Priszkulnik, L. (1995). A criança e a psicanálise: O” lugar" dos pais no atendimento infantil. Psicologia USP, 6(2), 95-102.

Ramos, M. (1998). Terapia familiar: O lugar do terapeuta. In M. Ramos (Ed.), Terapia de casal e família: O lugar do terapeuta (pp. 43-60). São Paulo, SP: Brasiliense.

Ramos, M. B. J., \& Maggi, N. R. (2011). O sintoma como expressão da subjetividade em crianças com dificuldades de aprendizagem: Alteridade como fator facilitador. Estudos de Psicanálise, (35), 65-73.

Rodrigues, C. M., \& Mishima-Gomes, F. K. T. (2013). As flores estão brotando: Atendimento infantil em consultas terapêuticas. Psicologia Clínica, 25(1), 89-100. doi:10.1590/S010356652013000100006

Silva, L. M., \& Ribeiro, D. P. S. A. (2011). O uso de mediadores dialógicos na clínica winnicottiana com crianças. In J. L. F. Abrão \& D. P. S. A. Ribeiro (Eds.), Psicanálise de crianças na universidade: Construindo práticas e delimitando fronteiras (pp. 57-71). São Paulo, SP: Arte \& Ciência.

Pires, J. F. S. C. (2002). Um estudo sobre o setting no atendimento psicanalítico: $D$. W. Winnicott e autores contemporâneos (Dissertação de mestrado, Universidade de São Paulo, SP, Brasil).

Telles, K. K. P. (2011). O manejo terapêutico em Winnicott: A clínica contemporânea (Tese de doutorado em Psicologia, Universidade Estadual Paulista, Faculdade de Ciências e Letras de Assis, SP, Brasil). Recuperado em http://base.repositorio.unesp.br/bitstream/ handle/11449/105601/telles_kkp_dr_assis.pdf? sequence $=1 \&$ isAllowed $=\mathrm{y}$
Telles, J. C. C. P., Sei, M. B., \& Arruda, S. L. S. (2010). Comunicação silenciosa mãe-bebê na visão winnicottiana: Reflexões teórico-clínicas. Aletheia, (33), 109-122.

Turato, E. R. (2005). Métodos qualitativos e quantitativos na área da saúde: Definições, diferenças e seus objetos de pesquisa. Revista de Saúde Pública, 39(3), 507-14. doi:10.1590/ S0034-89102005000300025

Winnicott, D. W. (1983a). Da dependência à independência no desenvolvimento do indivíduo. In D. W. Winnicott, $O$ ambiente e os processos de maturação: Estudos sobre a Teoria do Desenvolvimento Emocional (pp. 79-87). Porto Alegre, RS: Artes Médicas. (Original publicado em 1963)

Winnicott, D. W. (1983b). Distorção do ego em termos de falso e verdadeiro self. In D. W. Winnicott, $O$ ambiente e os processos de maturação: Estudos sobre a Teoria do Desenvolvimento Emocional (pp. 128-139). Porto Alegre, RS: Artes Médicas. (Original publicado em 1960)

Winnicott, D. W. (1975). O brincar e a realidade. Rio de Janeiro, RJ: Imago.

Winnicott, D. W. (2000). A tendência anti-social. In D. W. Winnicott, Da Pediatria à Psicanálise: Obras escolhidas (pp. 406-416). Rio de Janeiro, RJ: Imago. (Original publicado em 1956)

Recebido: 19/12/2014

$1^{a}$ revisão: $20 / 01 / 2015$

Aceite final: 28/01/2015 